\title{
Genetic Linkage of the Huntington's Disease Gene to a DNA Marker
}

\author{
James F. Gusella
}

\begin{abstract}
Recombinant DNA techniques have provided the means to generate large numbers of new genetic linkage markers. This technology has been used to identify a DNA marker that coinherits with the Huntington's Disease (HD) gene in family studies. The HD locus has thereby been mapped to human chromosome 4 . The discovery of a genetic marker for the inheritance of HD has implications both for patient care and future research. The same approach holds considerable promise for the investigation of other genetic diseases, including Dystonia Musculorum Deformans.
\end{abstract}

RÉSUMÉ: Les techniques d'ADN récombiné ont fourni le moyen de générer un grand nombre de nouveux marqueurs à liason génétique. Cette technologie a été employé afin d'identifier un marqueur d'ADN qui co-hérite avec le gène de la maladie de Huntington $(\mathrm{MH})$ dans les études familiales. Le lieu du gène de la $\mathrm{MH}$ a ainsi été localise sur le chromosome humain numéro 4. La découverte d'un marqueur génétique pour l'hérédité de $\mathrm{MH}$ a des implications pour la soin de patients ainsi que pour la recherche dans le futur. La même approche semble pleine de promesses pour l'investigation d'autres maladies génétiques, incluant la dystonie musculaire déformante.

Can. J. Neurol. Sci. 1984; 11:421-425

\section{Huntington's Disease}

Huntington's disease (HD) is a genetic neurodegenerative disorder first described by George Huntington in 1873 (Huntington, 1972; Hayden, 1981; Chase et al., 1979). The disease displays autosomal dominant inheritance with high penetrance. Numerous investigations have failed to identify the primary biochemical defect in this mystifying disorder. In HDgene carriers, apparently normal central nervous system development is followed by premature neuronal cell death, most notably in the basal ganglia. While chorea is the most widely recognized symptom of $\mathrm{HD}$, intellectual and psychological manifestations are also common. These can include memory loss, mood shifts, personality changes and chronic depression. Symptoms usually appear in the fourth to fifth decade of life and progress over a fifteen to twenty year span. Ultimately, the HD victim is totally physically disabled, and unable to communicate. Death often results from heart disease or complicated pneumonia following aspiration. Since the defect is not manifest until middle-age, many "at risk" individuals have already had children before they learn that they carry the disease gene. Although the prevalence of HD is approximately $10 / 100,000$ in most Caucasian populations, it has a severe impact on a far greater number of individuals, including "at risk" children, family and friends of patients. There is currently no effective therapy to cure this devastating disease, or to slow its inexorable progression.

\section{Recombinant DNA and Genetic Linkage Analysis}

In the past ten years, recombinant DNA techniques have revolutionized the study of human genetics. It is now possible to isolate specific human genes by cloning in bacteria and to directly analyze their DNA sequence. This technology therefore can permit the delineation of the primary cause of a genetic disease if the defective gene can be isolated. In most cases, however, it has only been possible to clone disease genes when there is already a knowledge of the altered protein involved. HD is typical of a multitude of genetic disorders for which no defective protein has yet been identified. In 1980, we chose HD as a model system to pursue a novel strategy of applying recombinant DNA technology to the study of human genetic disease. We set out to identify the chromosomal location of the HD gene based solely on the genetics of the disorder, with no assumptions concerning the product of the defective gene.

Our strategy evolved from one of the fundamental tenets of Mendelian genetics, the concept that alleles at two gene loci located close to each other on the same chromosome will be passed together with high frequency to progeny. Such genes

Presented at the Sth Dystonia Medical Research Foundation Workshop held in Calgary. Alberta. Canada. February 9-10. 1984.

From the Neurology Service and Genetics Unit, Massachusetts General Hospital and Department of Genetics. Harvard Medical School, Boston, Massachusetts Reprint requests to: James F. Gusella, Ph.D., Genetics Unit, Massachusetts General Hospital, Boston, Ma. 02114, U.S.A. 


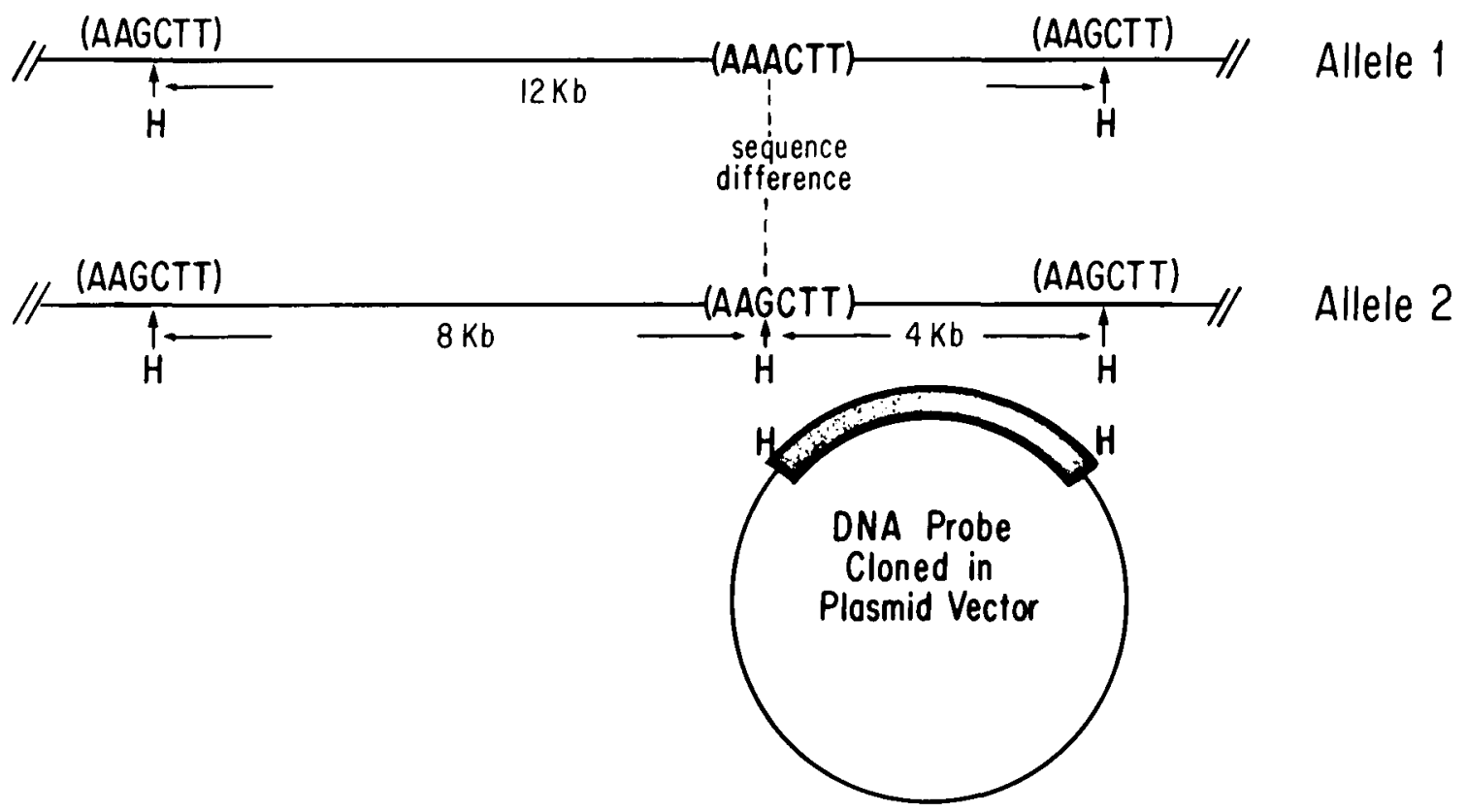

Figure 1 - This figure illustrates a hypothetical restriction fragment length polymorphism. The two alleles at this locus, l and 2 , correspond to absence or presence of a cleavage site for the enzyme HindIIl due to a single base difference in the DNA. The presence of allele 1 can be detected by monitoring for a $12 \mathrm{kilobase}$ ( $\mathrm{kb}$ ) fragment capable of reannealing with the cloned DNA probe shown in the Figure. The probe will hybridize to a 4 kb fragment when allele 2 is present. Since HindIII digestion of human genomic DNA produces approximately 1,000,000 other fragments, the specific fragments representing this locus must be detected in this mixture using the technique of "Southern" transfer and hybridization. This method is illustrated in Figure 2.

are said to be "genetically linked". Occasions when linked alleles are not inherited together result from a recombination event involving the exchange of material between chromosome arms during formation of the sex cell in the parent. The frequency with which recombination events occur between two linked genes can be used as a measure of the distance that separates them.

In our investigations, we undertook to locate another genetic characteristic that segregates with HD in family studies (Housman and Gusella, 1981, 1982). Discovery of such a linked marker would then allow us to infer the position of the HD gene in the human genome. Two requirements had to be fulfilled to guarantee our success in this endeavor. First, there had to be enough genetic markers available to test all regions of the genome for the presence of the HD locus. Second, we needed large HD families in order to obtain statistically significant scores for coinheritance of our tested markers.

Standard genetic linkage analysis had already been performed in HD families using classical polymorphic protein markers with no success (Pericak-Vance et al., 1979; Went and Volkers, 1979). These studies had, however, eliminated some $15 \%$ of autosomal regions as possible locations of the HD gene. Since the disorder is not sex-linked, the HD gene could not fall on the $\mathrm{X}$ chromosome. When we began the study, there was therefore $80 \%$ of the genome in which the disease gene might be located. Unfortunately, there were no genetic markers in these regions available to test for linkage to the HD locus.

We decided to apply recombinant DNA technology to the generation of new genetic markers to cover all regions of the genome. All inherited differences between individuals ultimately represent differences in the primary sequence of DNA. We reasoned that if recombinant DNA methods could be efficiently used to detect sequence variation in humans then these sequence polymorphisms could be used as genetic markers to trace the inheritance of genes located in their vicinity. The cornerstone of recombinant DNA technology, the restriction endonuclease, presents an ideal method of monitoring base sequence differences in DNA. These enzymes cut DNA in a manner that is exquisitely site-specific. Even a single base change in the sequence at the recognition sites for the enzyme will result in lack of cleavage at that location. (Figure 1) Differences in DNA sequence that affect restriction enzyme sites will therefore alter the sizes of fragments that are generated from that particular region of the genome.

A typical restriction enzyme digests human genomic DNA into perhaps one million fragments. It is imperative therefore to apply a method capable of detecting particular fragments that occur at only one position in the human genome. This technique known as Southern blotting involves transfer human genomic DNA that has been resolved by agarose gel electrophoresis to a solid membrane support by capillary action (Southern, 1975). The membrane is then hybridized with a radioactive probe molecule that represents one particular sequence of human DNA previously cloned in bacteria. The radioactive probe anneals to its complementary sequence on the filter membrane and detects a fragment whose size can thus be monitored. (Figure 2) Since the sequence chosen as probe occurs at only one position in the human genome it can represent a genetic marker for linkage of other genes to that particular site in the genome if it detects significant sequence variation. This sequence variation or polymorphism is detected as individual differences in the observed pattern of cleavage by restriction enzymes.

\section{HD Families}

In our early experiments, with randomly chosen anonymous DNA sequence probes, we found a very high degree of DNA 


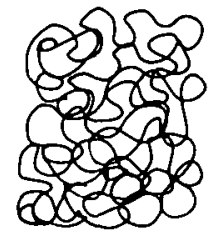

Genomic DNA

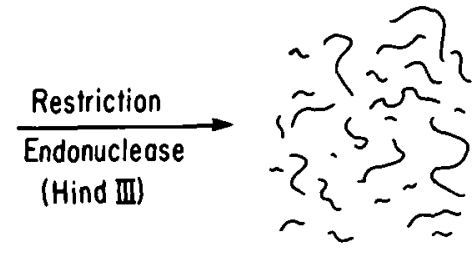

$\underset{\text { Electrophoresis }}{\stackrel{\text { Agarose Gel }}{\longrightarrow}}$

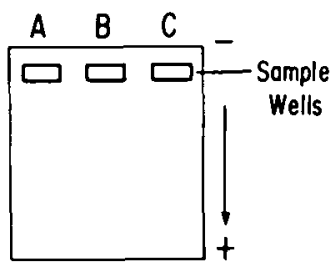

DNA

Tronsfer
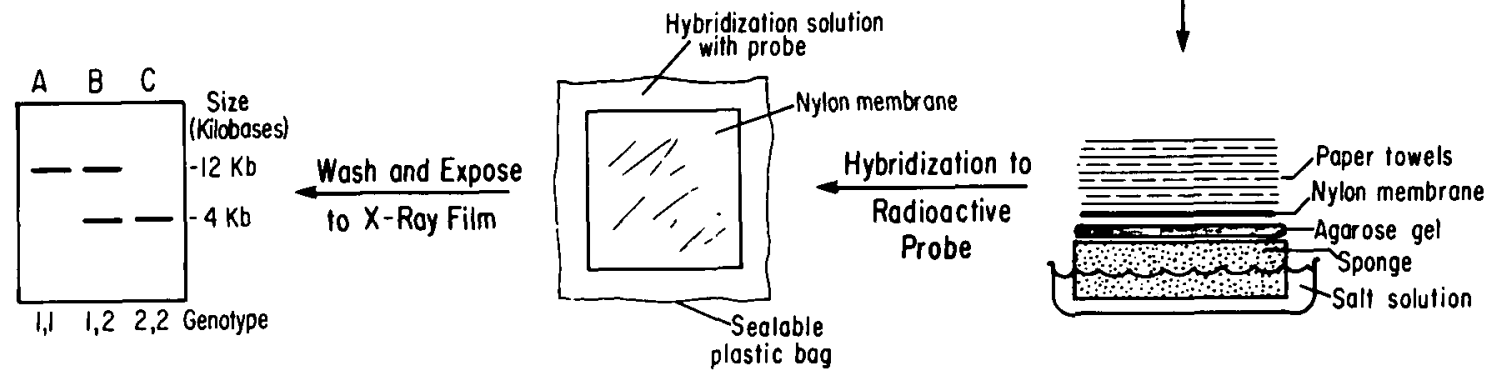

Figure 2 - In order to detect specific fragments in a restriction digest of human genomic DNA, the DNA fragments are applied to an agarose gel and resolved by size using electrophoresis. DNA from the gel is denatured and transferred by capillary action to a nylon membrane support. The DNA on the membrane is then exposed to a cloned DNA probe (see Figure 1) that has been made radioactive. The probe anneals to the DNA on the filter only where it detects a complementary sequence. In this case, hybridization takes place either to a $12 \mathrm{~kb}$ fragment or to a $4 \mathrm{~kb}$ fragment depending on the alleles present at this locus in the individual tested. The positions of the hybridizing fragments are detected by exposure of the washed filter to X-ray film.

sequence variation in humans (Gusella et al., 1983). As has been pointed out by Botstein and coworkers, DNA markers of this type could be used to develop a complete genetic linkage map of the human genome (Botstein et al., 1980). If however the technique is to be applied to a specific disease such as HD, it is essential to have families of adequate size to obtain a statistically significant score for linkage of the markers tested. We began our work on $\mathrm{HD}$ with an American family containing fourteen affected individuals available for study (Gusella et al., 1983). This family was obtained with the help of Dr. P.M. Conneally of Indiana University who maintains the National Huntington's Disease Research Roster. Subsequently, we were fortunate to gain access to a second much larger HD pedigree. This family, living in several communities on the shores of Lake Maracaibo in Venezuela was studied with the help of Dr. Nancy Wexler and members of the Venezuela-US Collaborative HD project (Wexler et al., in preparation). The pedigree consists of over 4,000 individuals of whom more than 3,000 are still living. Approximately 100 family members are currently affected by $\mathrm{HD}$ and several hundred members of the pedigree are at $50 \%$ risk for having inherited the disease. Lymphoblastoid cell lines were initiated as a permanent source of DNA for each informative member of both the US and Venezuelan families since we expected to test several hundred DNA markers to find one linked to HD. We have currently established lymphoblastoid cell lines from more than seven hundred members of the Venezuelan kindred. This pedigree now represents a tremendous resource not just for work on Huntington's disease but also for constructing a human genetic linkage map.

\section{The G8 Marker Locus}

Our initial investigations had indicated it would be possible with concerted effort to generate DNA markers in all regions of

\begin{tabular}{lccc}
\hline \multicolumn{3}{c}{ Table 1: RFLPs tested for linkage to H.D. } & \\
\hline \hline \multicolumn{1}{c}{ DNA } & CHROMOSOMAL & & LOD \\
MARKER & ASSIGNMENT & $\theta$ & SCORE \\
\hline D3S1 & 3 & 0.05 & -0.90 \\
G9 & 4 & 0.10 & -2.25 \\
G8 & 4 & 0.00 & +1.81 \\
D5S3 & 5 & 0.05 & -0.28 \\
D10S1 & 10 & 0.05 & -1.26 \\
NAG & 11 & 0.05 & -2.03 \\
HRAS1 & 11 & 0.05 & -2.29 \\
INS & 11 & 0.05 & -1.29 \\
D14S1 & 14 & 0.05 & -2.54 \\
DOSLC2 & 20 & 0.05 & -1.45 \\
pPW228C & 21 & 0.05 & -2.09 \\
pPW236B & 21 & 0.05 & -1.10 \\
G6 & 6 & 0.05 & -1.69 \\
\hline
\end{tabular}

the genome (Gusella et al., 1983). Furthermore, the families from which we had collected and banked samples were large enough to virtually guarantee that a marker in the correct vicinity could be efficiently detected. We therefore began to test DNA markers for linkage to HD. We chose thirteen random DNA probes known to detect DNA polymorphisms. Some of these probes were developed as part of this study, while others were obtained from other investigators. Each DNA marker was tested for the segregation of genotypes in the American HD pedigree and was analyzed for linkage to Huntington's disease. (Table 1) We were able to exclude the HD gene from close linkage to several markers but were surprised to obtain a positive score for linkage of the marker G8 to HD. The maximum score occurred at $0 \%$ recombination indicating that the computer analysis failed to detect any obligate recombinants in the American pedigree. 


\section{G8 Locus on Chromosome 4}

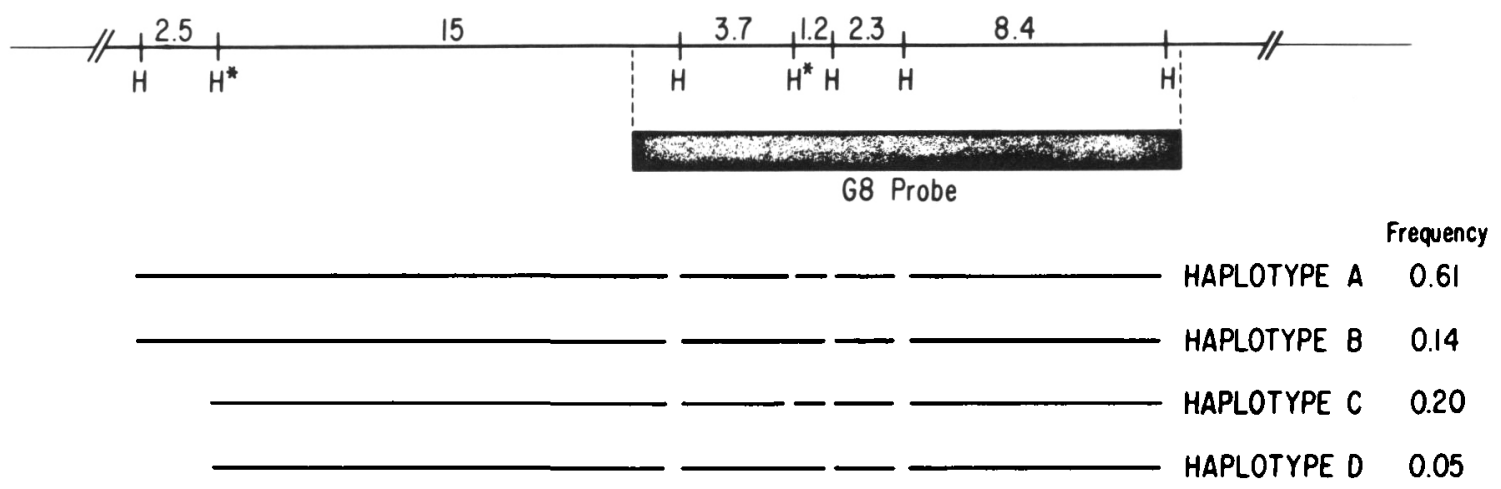

Figure 3 - The G8 probe covers 17.6 kilobases of human DNA from chromosome 4 and hybridizes to the fragments shown in this map. The $2.3 \mathrm{~kb}$ and $8.4 \mathrm{~kb} H$ indIII fragments are invariant. The other fragments generated depend on the presence or absence of two polymorphic HindIII sites marked by an asterisk. The population frequencies for each of the four haplotypes, $A, B, C$, and $D$, are shown. The haplotypes present in a given individual are monitored as shown in Figure 2 .

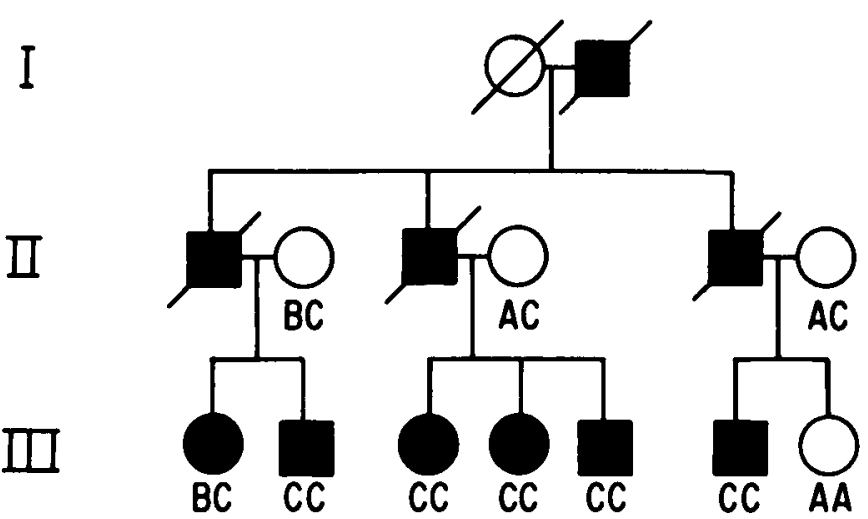

Figure 4-A small portion of the Venezuela pedigree is shown with the genotypes at the G8 locus to illustrate that the HD gene is cosegregating in this family with the $C$ haplotype of the marker. Legend: circle = female; square $=$ male $;$ darkened symbol $=$ affected with $H D ;$ slashed symbol $=$ deceased.

While this result was encouraging it was not sufficient to prove linkage of the marker to the disease locus. We therefore typed a small portion of the Venezuela family in order to confirm our initial data. From this analysis the data yielded a relative likelihood of approximately 5,000,000:1 in favor of linkage of the G8 marker to the HD locus. The best estimate for the distance of the marker from the disease gene was still $0 \%$ recombination. This score indicated that we had indeed identified a DNA marker tightly linked to the HD gene (Gusella et al., 1983).

The $\mathbf{G} 8$ probe is an anonymous (no known coding function) cloned DNA segment probe from human chromosome 4 that detects two independent HindIII site polymorphisms in human genomic DNA (Figure 3). The two HindIII site polymorphisms are separated from each other in the genome by approximately 18,000 base pairs. Since these two sites are so close together in the genome, four possible haplotypes consisting of presence or absence of cutting by HindIII at each of these two sites were defined. Each of the four haplotypes was detected at a significant frequency in the general population. Figure 4 represents a small portion of the Venezuela pedigree that demonstrates cosegregation of the C haplotype at the G8 locus with the HD gene.

\section{Implications}

We are currently using the G8 probe to investigate a number of questions concerning the genetics and expression of the HD gene. We are attempting to obtain more precise mapping of the DNA marker in order to identify the exact site of the HD gene on chromosome 4. The marker is also being used to type additional informative members of the large Venezuelan kindred, as well as members of other HD families. These studies will yield a better estimate of the recombination frequency (and therefore genetic distance) between the G8 locus and the HD gene. One particular family in the Venezuela pedigree, where both parents are affected by $\mathrm{HD}$, is also being investigated to determine whether any of the children are homozygous for the HD allele.

The discovery of this linkage marker should lead to development of an inheritance test for presymptomatic diagnosis of HD. This would allow some at risk individuals with appropriate living family members to determine whether or not they are gene carriers long before initial symptoms appear. Such a test could also be applied to prenatal detection of HD. We are currently analyzing the marker using additional HD families obtained with the help of a number of investigators in order to rule out the possibility of nonallelic genetic heterogeneity in HD. Until it is demonstrated that HD is due to a defective locus linked the G8 marker in all families, it will not be possible to use our probe for presymptomatic diagnosis of the disease in small pedigrees. At the same time we will be obtain a more accurate estimate for the distance of our marker from the disease locus.

Although the initial impact of this linkage will be to improve diagnosis, it will have another potentially more important impact on the direction in research in HD. It should now be possible to devise recombinant DNA cloning strategies based on the mapped location of the disease gene that will allow isolation and identification of the defective gene. This would reverse the standard route of identifying a defective protein and subsequently using the information to clone the disease gene. In this case it might be possible to clone the disease gene and thereby identify the protein defect involved in the disorder. 
The approach we have used to investigate HD can be used in any human genetic disorder that shows a clear pattern of inheritance and for which appropriate family material is available. We are currently involved in a collaborative project with $\mathrm{Dr}$. Xandra Breakefield to determine the map location of the gene causing autosomal dominant Dystonia Musculorum Deformans. The rate of discovery of new DNA markers in laboratories around the world makes it likely that a human linkage map covering all regions of all chromosomes will be available within only a few years. It is therefore highly likely that the map location of the dystonia gene will be identified if pedigrees of significant size can be identified and samples banked.

\section{ACKNOWLEDGEMENTS}

This work was supported by NINCDS grants NS 16367 (Huntington's Disease Center Without Walls) and NS20012, by a grant from the Hereditary Disease Foundation, and by the Julieanne Dorn Fund for Neurological Research.

\section{REFERENCES}

Botstein D, White RL, Skolnick M, Davis R (1980) Construction of a genetic linkage map in man using restriction fragment length polymorphisms. 32 : $314-331$.
Chase TN, Wexler NS, Barbeau A, eds (1979) Huntington's disease. Adv. Neurol. 23 (Raven Press, New York).

Gusella JF, Wexler NS, Conneally PM, et al. (1983) A polymorphic DNA marker genetically linked to Huntington's disease. Nature 306: 234-238.

Gusella JF, Tanzi R, Anderson MA, et al. (1983) In: Banbury Report 14: "Recombinant DNA applications to human disease" C.T. Caskey, R.L. White eds. The use of restriction fragment length polymorphisms to map the Huntington's disease gene. (Cold Spring Harbor, New York) pp. 261-266.

Hayden MR (1981) Huntington's Chorea (Springer, New York).

Housman D, Gusella JF (1982) In: "Molecular Genetic Neuroscience" F.O. Schmitt, S.J. Bird, F.E. Bloom, eds. (Raven, New York) pp. 415-424. Molecular genetic approaches to neural degenerative disorders.

Housman D, Gusella J (1981) In "Genetic Strategies for Psychobiology and Psychiatry", E.S. Gershon, S. Matthysse, X.O. Breakfield, R.D. Ciaranello, eds. (Boxwood). Use of recombinant DNA techniques for linkage studies in genetically based neurological disorders.

Huntington G (1972) Med. Surg. Reporter 26: 317-321.

Ott J (1974) Estimation of the recombination fraction in human pedigrees: efficient computation of the likelihood for human linkage studies. Am. J. Hum. Gen. 26: 588-597.

Pericak-Vance MA, Conneally PM, Merritt AD, et al. (1979) Genetic linkage in Huntington's disease. Adv. Neurol. 23: 59-72.

Southern EM (1975) Detection of specific sequences among DNA fragments separated by gel electrophoresis. J. Mol. Biol. 98: 503-517.

Went LN, Volkers WS (1979) Genetic linkage. Adv. Neurol. 23: 37-42. 